\title{
Spectrum of Etiology of Hematemesis among Pediatric Populations in Eastern India
}

\author{
Dr Niloy Kumar Das ${ }^{1}$, Dr Kapildev Mondal ${ }^{2 *}$, Dr Arijit Sinha ${ }^{3}$ \\ ${ }^{1}$ Assistant Professor, Pediatric Medicine, ESI-PGIMSR, ESICMC \& ESICH \& ODC (EZ), Kolkata, India \\ Ex Senior Resident Pediatric Medicine, IPGME\&R, SSKM Hospital, Kolkata, India \\ ${ }^{2}$ Assistant Professor, General Medicine, Murshidabad Medical College \& Hospital, West Bengal, India \\ Ex Senior Resident of General Medicine, IPGME\&R, SSKM Hospital, Kolkata, India \\ ${ }^{3}$ Assistant Professor, General Medicine, Murshidabad Medical College \& Hospital, West Bengal India \\ *Corresponding Author: Dr Kapildev Mondal
}

\begin{abstract}
Objective: To find out the causes of hematemesis in pediatric populations in eastern India. Methodology: Children below 12 years of age who presented with hematemesis were included in the study after proper consent. Study period was from January 2012 to December 2012 in Kolkata, India. Results: 20 patients were included, male:female was 13:7.Most common cause was variceal bleeding (30\%) followed by idiopathic in $25 \%$ cases. Esophagitis, gastritis, duodenal ulcer was found in $25 \%$ cases and mostly in older age group.10 \% patients required blood transfusion. There was no mortality. Conclusion: Facility of upper GI endoscopy is very much effective for diagnosis as wll as treatment of such cases.
\end{abstract}

Keywords: hematemesis, pediatric, upper gastro intestinal endoscopy

\section{Introduction}

Hematamesis means bloody vomitus. It is the most common manifestation of upper gastrointestinal bleeding.(1)It is usually associated with passage of altered blood per rectum ;sometimes with shock and death. It is quite alarming for the patient as well as care taker. Though most cases are self-limiting and benign it may turns into medical as well as surgical emergency.(2) Mucosal lesions, variceal bleeding and in intensive care unit infections and drugs are predominant cause.(3)There is considerable variation in etiology of UGI bleeding in different studies. $(4,5,6)$ Aim of this study was to review the common causes of of UGI bleeding in children in eastern India and whether it is differ from previous studies of India as well as other country.

\section{Methodology}

All patients who admitted with hematemesis below age of 12 years at IPGMER\&SSKM Hospital, Kolkata from January 2012 to December 2012 was included in the study after taking proper consent. Information like age, sex, frequency of bleeding, presence of melena, hematochezia, drug intake, any comorbid condition were noted. They were thoroughly examined for presence of shock, any underlying systemic disease.

All patients were undergone following blood test like complete blood count including platelet, PT, a PTT.USG abdomen and upper GI endoscopy were done where indicated.

Neonates were excluded since they are admitted in another set up.

\section{Results}

Total 20 patients were included. Mean age was 7.6+- 3.5 years. Out of 20 patients, 13 were male, 7 female. 11(55\%) patients were presented for the first time. Extra hepatic portal venous obstruction (EHPVO) mainly responsible for recurrent bleeding. Esophageal varices was the most common cause of hematemesis in $6(30 \%)$ cases- 5 cases due to EHPVO and 1 case due to cirrhosis of liver followed by idiopathic $5(25 \%)$ cases, $3(15 \%)$ cases due to esophagitis and gastritis, $2(10 \%)$ cases due to duodenal ulcer, $1(5 \%)$ case due to gastric ulcer. 1 case of Liver abcess, 1 dengue shock syndrome and case of HSP was found to be associated with hematemesis.

Cirrhosis and dengue shock syndrome patients had prolonged PT and APTT, with thrombocytopenia. In 4 cases all investigations were normal.1 patient of HSP developed UGI bleeding but his coagulation profile, USG abdomen, UGI endoscopy was normal. Liver abcess patient developed coagulopathy.

All 6 variceal patients undergone variceal ligation as urgent basis.2 (10\%) patients required blood transfusion. There was no mortality.

Table: Age wise distribution of causes of UGI bleeding

\begin{tabular}{|l|r|r|}
\hline & \multicolumn{1}{l|}{$<6$ years } & $>6$ years \\
\hline Causes & \multicolumn{1}{|c|}{$\mathrm{n}=7$} & $\mathrm{n}=13$ \\
\hline EHPVO & $1(14.3 \%)$ & $4(30.8 \%)$ \\
\hline Chirrosis of liver & $1(14.3 \%)$ & 0 \\
\hline Esophagitis, gastritis & 0 & $3(23.1 \%)$ \\
\hline Duodenal ulcer & 0 & $2(15.4 \%)$ \\
\hline Mallory Weiss syndrome & $1(14.3 \%)$ & 0 \\
\hline Idiopathic & $3(42.8 \%)$ & $2(15.45 \%)$ \\
\hline Liver abcess & 0 & $1(7.7 \%)$ \\
\hline Dengue shock syndrome & 0 & $1(7.7 \%)$ \\
\hline HSP & $1(14.3 \%)$ & 0 \\
\hline
\end{tabular}

UGI-upper gastro intestinal

EHPVO=Extra hepatic portal venous obstruction $\mathrm{HSP}=\mathrm{Henoch}$ Schonlein Purpura

\section{Volume 6 Issue 1, January 2017




\section{International Journal of Science and Research (IJSR) \\ ISSN (Online): 2319-7064}

Index Copernicus Value (2015): 78.96 | Impact Factor (2015): 6.391

\section{Discussion}

Upper GI bleeding may be unnoticed by patient if it present with occult bleeding. It may be confirmed by Nasogastric lavage. Again it may be negative if bleeding ceases or bleeding occur distal to pylorus. So exact incidence of upper GI bleeding is unknown. Again most of the studies were done in Pediatric Intensive Care Unit. Though hematemesis is easily observable but no data is available exclusively for hematemesis. The differential diagnosis are hemoptysis i.e.bloody cough, posterior nasal bleeding.

Regarding etiology in western countries most common cause were gastric duodenal ulcer while in India predominant cause was variceal bleeding.(6-9)Our study also corroborated with that. Even after almost 2 decades most common etiology remained same. Though another study from Iran a developing country showed gastric erosion was the leading cause like developed country.(4)Incidence of gastritis, esophagitis and gatro duodenal ulcer increases with age. In our study no etiology was found in $5(25 \%$ )cases. Previous study from India(6) Iran(4) had similar incidence $25 \%$ and $20 \%$ respectively.

Upper GI endoscpy was found to be very much efficient in diagnosis as well as treatment modality. But ligation only done in cases of varices. Other caeses ceased to bleed after sometimes with conservative management like intravenous proton pump inhibitor, intravenous fluid and rarely blood transfusion.

\section{Conclusion}

So in cases of pediatric hematemesis patients should ideally be managed in a set up where pediatric upper GI endoscopy is available because in India variceal bleeding still remains the leading cause of upper GI bleeding.

\section{Acknowledgment}

Thanks to MSVP of SSKM \& IPGME\&R hospital, all doctor, sister and staff of Pediatric Medicine, IPGME\&R, SSKM Hospital, Kolkata, India

\section{Source of Fund}

Ours Own

\section{References}

[1] OkelloT.R.Upper gastrointestinal endoscopic find9. ings in adolescents at Lacor hospital, UgandaAfr Health Sci .2006, 6(1):39-42

[2] Fleisher G, Ludwig S, ed.Gastrointestinalbleed1. ing. Pediatric Emergency Medicine, 4th ed. Philadelphia: Lippincott Williams \& Wilkins; 2000;30:275-282.

[3] Arora NK, Ganguly S, Mathur P, Ahuja A, Patwari A. Upper gastrointestinal bleeding: etiology and management. Indian J Pediatr 2002; 69: 155-168

[4] Dehghani SM, 4. Haghighat M, Imanieh MH, Tabebordbar MR Upper Gastrointestinal Bleeding in Children in Southern Iran Indian J Pediatr2009 Jun;76(6):635-8.
[5] EL Mouzan MI, Abdullah AM, AI- Mofleh IA. Yield of endoscopy in children with hematemesis. Trop Gastroenterol 2004; 25: 44-46.

[6] Mittal SK, Kalra KK, Aggarwal V. Diagnostic upper GI endoscopy for hemetemesis in children: experience from a pediatric gastroenterology centre in north India. Indian J Pediatr 1994; 61 : 651-654.

[7] Rodgers BM. Upper gastrointestinal hemorrhage. Pediatr Rev 1999; 20: 171-174.

[8] Cox K, Ament ME. Upper gastrointestinal bleeding in children and adolescents. Pediatrics 1979; 63: 408-413.

[9] Yachha SK, Khanduri A, Sharma BC, Kumar M. Gastrointestinal bleeding in children. J Gastroenterol Hepatol 1996; 11 : 903-907. 